\title{
Investigation of Combined Pollution between Malathion and a Variety of Pollutants Based on the Fractional Factorial Design (Resolution IV)
}

\author{
Bingchuan Cheng ${ }^{1,2}$, Shanshan $\mathrm{Li}^{1,2,3}$, Meng Wang ${ }^{1,2}$, Yu Li ${ }^{1,2 *}$ \\ 'MOE Key Laboratory of Regional Energy Systems Optimization, \\ North China Electric Power University, Beijing 102206, China \\ ${ }^{2}$ Resources and Environmental Research Academy, North China Electric Power University, Beijing 102206, China \\ ${ }^{3}$ Department of Civil and Environmental Engineering, University of Louisville, Louisville, KY 40292, United States
}

Received: April 7, 2015

Accepted: May 25, 2015

\begin{abstract}
In order to reveal the combined pollution characteristics of malathion adsorption onto the surficial sediments with pesticides (dimethoate, metalaxyl, atrazine, malathion, prometryn) and heavy metals $(\mathrm{Cu}, \mathrm{Zn}, \mathrm{Pb}$, $\mathrm{Cd}, \mathrm{Ni}$ ) present, a $2^{10-5}$ fractional factorial design of resolution IV was employed to identify non-interactive effects and two-way interactions of the chosen factors on malathion adsorption. The missing values of malathion adsorption in the experiment were approximated using the algorithm of back propagation neural network. It was found that $\mathrm{Zn}(13.69 \%)$, atrazine (8.76\%), and metalaxyl $(5.99 \%)$ have significant positive effect $(\alpha=0.05)$ on the malathion adsorption; $44.92 \%$ of the total contribution to malathion adsorption came from the non-interactive effects, while $55.08 \%$ was from the two-way interactions (Cu×metalaxyl, $\mathrm{Zn} \times$ atrazine, $\mathrm{Cu} \times$ prometryn, $\mathrm{Pb} \times \mathrm{Cu}, \mathrm{Cu} \times$ atrazine, and $\mathrm{Cu} \times \mathrm{Ni}$ ). Notably in the two-way interactions, $\mathrm{Zn} \times$ atrazine $(12.93 \%)$ and $\mathrm{Cu} \times$ prometryn $(5.97 \%)$ have a strong synergistic effect on malathion adsorption, while $\mathrm{Pb} \times \mathrm{Cu}(15.80 \%), \mathrm{Cu} \times$ atrazine $(7.82 \%), \mathrm{Cu} \times$ metalaxyl (6.63\%), and $\mathrm{Cu} \times \mathrm{Ni}(5.93 \%)$ present intense antagonisms to malathion adsorption. The whole philosophy could be used as a new methodology in accessing the degree of combined pollution and the effect of multiple pollutants on the selected pollutants.
\end{abstract}

Keywords: malathion, surficial sediments, combined pollution, fractional factorial design, interactive effect

\section{Introduction}

With the rapid development of industry and agriculture, pollution problems have become increasingly prominent [1]. Pesticides and heavy metals discharged into the environment are cumulative $[2,3]$, which has caused serious pollution to the atmosphere [4], water [5], and soil [6], and

*e-mail: liyuxx8@hotmail.com threatens the health of animals, plants, and humans [7, 8]. We rarely find only one pollutant or sole pollution in our environment, and combined pollution is most likely in every case [9]. Combined pollution would further pollute the environment because the co-existence of pollutants has changed their environmental behavior and eco-toxicity by the interaction effect [10]. Along with the change of environment, pollutants in the environment migrate in a certain environmental medium or between different environmental 
media [11]. Combined pollution could change the pollutants' migration pathways and their biological effect [12], with $\mathrm{Pbs}$ to the combined pollution among pesticides [13], heavy metals, and other pollutants being a key issue of concern to researchers for a long time [14].

Surficial sediment as an important carrier in migration of many pollutants in natural water is also a main destination of pollutants in the water [15]. It can gather a variety of heavy metals, pesticides, and other pollutants from the water environment [16]. Therefore, scholars from various countries have made a lot of research to study the adsorption behavior of heavy metals and pesticides in the watersediment environment [17], including the content study on pesticides and heavy metals in different regional sediments [18], the mechanism analysis of pollutants' adsorption onto sediments [19], and adsorption mechanism analysis of pollutants onto the sediments under combined pollution cases. David et al. studied the interacting effects of $\mathrm{pH}$, phosphate, and time on the release of arsenic from As-rich riverbed sediments. Arsenic release edges and kinetic release experiments, in the absence and presence of phosphate, coupled with sequential extraction procedures, SEM/EDX analyses, and geochemical calculations, were carried out to evaluate and to elucidate the mechanisms involved [20]. Guo et al. measured the effects of $\mathrm{Cr}(\mathrm{VI})$ and $\mathrm{As}(\mathrm{V})$ on lindane sorption. Results show that more lindane is adsorbed by biofilms than by suspended particles and sediments on a total mass basis, whereas the sediments had a higher lindane sorption capacity per unit mass organic carbon than suspended particles and biofilms. Co-occuring $\mathrm{Cr}$ (VI) or As (V) decreased lindane sorption on the biofilms by about $48 \%$ [21].

Organophosphorus pesticides have the advantages of being economic, effective, and convenient, and they are widely used in prevention and control of plant diseases and pests of agriculture [22,23]. Some kinds of the non-durable organophosphorus pesticides also have a longer survival period in certain environmental conditions and would accumulate in the animal body [24]. Malathion is an organophosphorus pesticide with highly selective features [25]. It is a highly toxic pesticide for aquatic organisms and the human immune system [26], and it is an important monitoring project in the water environment. A study shows that its residue has been detected in water bodies [27].

At this point, the biggest challenge is how to reveal the combined pollution mechanism from their adsorption process onto the surficial sediments. Wang et al. used a fractional factorial design of resolution III method to explore the combined pollution rules of $\mathrm{Zn}$ and atrazine onto surficial sediments [28]. But it didn't show a clear effect from the non-interactive pollutant and the two-way interactions among different pollutants.

In this study, we used a $2^{10-5}$ fractional factorial design of resolution IV method and a multiple linear regression adsorption model to reveal the composite contaminations characteristic of malathion adsorption onto the surficial sediments in a contamination system composed by pesticides (dimethoate, metalaxyl, atrazine, marathon, and prometryn) and heavy metals $(\mathrm{Cu}, \mathrm{Zn}, \mathrm{Pb}, \mathrm{Cd}$, and $\mathrm{Ni}$ ).
It would provide a theoretical support for revealing the combined pollution mechanism between pesticides and heavy metals. In addition, the back propagation (BP) neural network was applied for predicting the missing values of malathion adsorption in the experiment [29].

\section{Experiments and Methods}

\section{Reagents and Apparatus}

The malathion used was $99.5 \%$ pure in the experiments and it was supplied by the Agro-environmental Protection Institute of China's Ministry of Agriculture. Methanol with HPLC (SHIMADZU, model: LC20A) grade was purchased from Fisher Co. USA. All other chemicals were of analytical grade. Deionized water was used for all experiments.

\section{The Collection and Pre-Treatment of Sediment Samples}

Wang et al. (one member of our research group) already revealed the combined pollution characteristic of zinc adsorption onto the surficial sediments [30]. Considering the continuity of the study, we selected the same sediment sampling site: the Songhua River in Jilin, China. Samples were dug by a type sampler, and the sampling depth was sediment surface layer $(0-5 \mathrm{~cm})$. Every sample was made by mixing four samples taken from $20 \mathrm{~cm}$ around the sampling point. Then all samples were mixed and combined uniformly as a sample. After the sample dried, and plant and animal residues (i.e. gravel, wood chips, weeds, and other debris) removed, the sediment samples were packed in plastic bags. Then the samples would be transferred into the laboratory as soon as possible, dried at room temperature, and ground with a mortar pestle. The final step was letting the sample dry in a cool ventilated place, refrigerated or lyophilized at $4^{\circ} \mathrm{C}$.

\section{Experimental Methods and Design}

The module (Design of Experimental) in Minitab software package was adopted in experimental design and statistical analysis. In this experiment, representative heavy metals ( $\mathrm{Pb}, \mathrm{Cu}, \mathrm{Zn}, \mathrm{Cd}$, and $\mathrm{Ni}$ ) and pesticides (dimethoate, metalaxyl, atrazine, marathon, and prometryn) were selected as study factors, and malathion was chosen as the target pollutant factor. This study used a $2^{10-5}$ fractional factorial design of resolution IV with low order confounding. Concentrations for the pollution factor must reach the detection limit, and must be under the solubility of solution. Therefore, the pollution factor levels were determined through the preliminary experiment. Factor levels are shown in Table 1. Thirty-two experiments were taken as a unit, and the parallel sample experiment was set up. Through the statistical analysis software (Minitab), a $2^{10-5}$ fractional factorial design table (Table 2) was summarized. Based on the principles of fractional factorial design in 
Table 1. The high and low levels of five heavy metals and five pesticides $(\mu \mathrm{mol} / \mathrm{L})$.

\begin{tabular}{|l|c|c|c|c|c|}
\hline \multicolumn{1}{|c|}{ Select level $(\mu \mathrm{mol} / \mathrm{L})$} & Dimethoate & Metalaxyl & Atrazine & Malathion & Prometryn \\
\hline Low level $(-)$ & 10 & 10 & 10 & 10 & 10 \\
\hline High level $(+)$ & 25 & 25 & 25 & 25 & 25 \\
\hline Select level $(\mu \mathrm{mol} / \mathrm{L})$ & $\mathrm{Cu}$ & $\mathrm{Zn}$ & $\mathrm{Pb}$ & $\mathrm{Cd}$ & $\mathrm{Ni}$ \\
\hline Low level $(-)$ & 60 & 60 & 60 & 60 & 60 \\
\hline High level $(+)$ & 150 & 150 & 150 & 150 & 150 \\
\hline
\end{tabular}

Table 2. The $2^{10-5}$ fractional factorial design of ten pollutants adsorbed onto the sediments.

\begin{tabular}{|c|c|c|c|c|c|c|c|c|c|c|}
\hline & $\mathrm{Cu}$ & $\mathrm{Zn}$ & $\mathrm{Pb}$ & $\mathrm{Cd}$ & Ni & Atrazine & Malathion & Prometryn & Dimethoate & Metalaxyl \\
\hline 1 & 1 & 1 & 1 & 1 & 1 & 1 & 1 & 1 & 1 & 1 \\
\hline 2 & -1 & -1 & 1 & -1 & -1 & -1 & -1 & 1 & -1 & -1 \\
\hline 3 & 1 & 1 & -1 & 1 & -1 & -1 & 1 & -1 & 1 & 1 \\
\hline 4 & 1 & 1 & -1 & -1 & -1 & 1 & 1 & 1 & -1 & -1 \\
\hline 5 & 1 & -1 & 1 & -1 & -1 & 1 & 1 & -1 & 1 & -1 \\
\hline 6 & -1 & 1 & 1 & 1 & -1 & -1 & 1 & 1 & 1 & -1 \\
\hline 7 & 1 & 1 & -1 & 1 & 1 & -1 & -1 & 1 & -1 & -1 \\
\hline 8 & 1 & -1 & 1 & 1 & 1 & -1 & -1 & -1 & 1 & -1 \\
\hline 9 & -1 & -1 & 1 & 1 & -1 & 1 & -1 & -1 & 1 & 1 \\
\hline 10 & -1 & 1 & -1 & 1 & -1 & 1 & -1 & 1 & -1 & 1 \\
\hline 11 & 1 & 1 & -1 & -1 & 1 & 1 & -1 & -1 & 1 & 1 \\
\hline 12 & -1 & 1 & -1 & -1 & -1 & -1 & -1 & -1 & 1 & -1 \\
\hline 13 & 1 & -1 & 1 & -1 & 1 & 1 & -1 & 1 & -1 & 1 \\
\hline 14 & 1 & -1 & 1 & 1 & -1 & -1 & 1 & 1 & -1 & 1 \\
\hline 15 & 1 & -1 & -1 & 1 & -1 & 1 & -1 & 1 & 1 & -1 \\
\hline 16 & -1 & -1 & 1 & -1 & 1 & -1 & 1 & -1 & 1 & 1 \\
\hline 17 & -1 & 1 & 1 & -1 & -1 & 1 & 1 & -1 & -1 & 1 \\
\hline 18 & -1 & -1 & -1 & 1 & -1 & -1 & 1 & -1 & -1 & -1 \\
\hline 19 & -1 & 1 & -1 & -1 & 1 & -1 & 1 & 1 & -1 & 1 \\
\hline 20 & -1 & 1 & -1 & 1 & 1 & 1 & 1 & -1 & 1 & -1 \\
\hline 21 & -1 & 1 & 1 & -1 & 1 & 1 & -1 & 1 & 1 & -1 \\
\hline 22 & -1 & -1 & -1 & -1 & -1 & 1 & 1 & 1 & 1 & 1 \\
\hline 23 & 1 & 1 & 1 & -1 & -1 & -1 & -1 & 1 & 1 & 1 \\
\hline 24 & -1 & 1 & 1 & 1 & 1 & -1 & -1 & -1 & -1 & 1 \\
\hline 25 & 1 & -1 & -1 & -1 & 1 & -1 & 1 & 1 & 1 & -1 \\
\hline 26 & -1 & -1 & 1 & 1 & 1 & 1 & 1 & 1 & -1 & -1 \\
\hline 27 & 1 & 1 & 1 & -1 & 1 & -1 & 1 & -1 & -1 & -1 \\
\hline 28 & 1 & -1 & -1 & -1 & -1 & -1 & -1 & -1 & -1 & 1 \\
\hline 29 & -1 & -1 & -1 & -1 & 1 & 1 & -1 & -1 & -1 & -1 \\
\hline 30 & 1 & 1 & 1 & 1 & -1 & 1 & -1 & -1 & -1 & -1 \\
\hline 31 & 1 & -1 & -1 & 1 & 1 & 1 & 1 & -1 & -1 & 1 \\
\hline 32 & -1 & -1 & -1 & 1 & 1 & -1 & -1 & 1 & 1 & 1 \\
\hline
\end{tabular}


Minitab software and through the interactions of $\mathrm{Pb}, \mathrm{Cu}$, $\mathrm{Zn}$, prometryn, and marathon, and the form of generating element, the concentration levels of $\mathrm{Cd}, \mathrm{Ni}$, atrazine, metalaxyl, and dimethoate were listed as follows (we used " $\times$ " to express the two-way interaction in the equation):

$\mathrm{Cd}=\mathrm{Pb} \times \mathrm{Cu} \times \mathrm{Zn} \times$ prometryn

$\mathrm{Ni}=\mathrm{Pb} \times \mathrm{Cu} \times \mathrm{Zn} \times$ malathion

atrazine $=\mathrm{Pb} \times \mathrm{Cu} \times$ prometryn $\times$ malathion

metalaxyl $=\mathrm{Pb} \times \mathrm{Zn} \times$ prometryn $\times$ malathion

dimethoate $=\mathrm{Cu} \times \mathrm{Zn} \times$ prometryn $\times$ malathion

The concentrations of 10 different kinds of pollutant solution were mixed according to the corresponding requirements of randomized trial in Table 2 . Twenty $\mathrm{ml}$ solutions were extracted from mixed solutions of 64 groups and were separately fitted to 64 conical flasks containing $0.5000 \pm 0.0001 \mathrm{~g}$ sediment samples. After oscillation for $48 \mathrm{~h}$, mixed solutions were filtered with $0.22 \mu \mathrm{m}$ filter paper. Levels of malathion in the solution before and after adsorption were measured by HPLC, and the adsorption amount of malathion was calculated by subtraction, i.e., the adsorption amount of malathion calculated by the subtraction including the soil background values, and the effects of soil background values on the experimental results were avoided.

It can be seen from Design and Analysis of Experiments written by Douglas C. Montgomery, that the priority is to investigate the interaction effect of low order, a principle of statistics [31]. When the factor is too much, interactions more than two-way could be ignored. This premise can reduce the number of experimental groups and improve efficiency and accuracy. Without considering the interactions more than two-way, there is no alias for the non-interaction effects in the fractional design of resolution IV. But the two-way interactions had an alias as follows:

$\mathrm{Pb} \times \mathrm{Cu}=$ metalaxyl $\times$ dimethoate

$\mathrm{Pb} \times \mathrm{Zn}=$ atrazine $\times$ dimethoate

$\mathrm{Pb} \times$ prometryn $=\mathrm{Ni} \times$ dimethoate

$\mathrm{Pb} \times$ malathion $=\mathrm{Cd} \times$ dimethoate

$\mathrm{Pb} \times \mathrm{Cd}=$ malathion $\times$ dimethoate

$\mathrm{Pb} \times \mathrm{Ni}=$ prometryn $\times$ dimethoate

$\mathrm{Pb} \times$ atrazine $=\mathrm{Zn} \times$ dimethoate

$\mathrm{Pb} \times$ metalaxyl $=\mathrm{Cu} \times$ dimethoate

$\mathrm{Pb} \times$ dimethoate $=\mathrm{Cu} \times$ metalaxyl $=\mathrm{Zn} \times$ atrazine $=$ prometryn $\times \mathrm{Ni}=$ malathion $\times \mathrm{Cd}$

$\mathrm{Cu} \times \mathrm{Zn}=$ atrazine $\times$ metalaxyl

$\mathrm{Cu} \times$ prometryn $=\mathrm{Ni} \times$ metalaxyl

$\mathrm{Cu} \times$ malathion $=\mathrm{Cd} \times$ metalaxyl

$\mathrm{Cu} \times \mathrm{Cd}=$ malathion $\times$ metalaxyl

$\mathrm{Cu} \times \mathrm{Ni}=$ prometryn $\times$ metalaxyl

$\mathrm{Cu} \times$ atrazine $=\mathrm{Zn} \times$ metalaxyl

$\mathrm{Zn} \times$ prometryn $=\mathrm{Ni} \times$ atrazine

$\mathrm{Zn} \times$ malathion $=\mathrm{Cd} \times$ atrazine

$\mathrm{Zn} \times \mathrm{Cd}=$ malathion $\times$ atrazine

$\mathrm{Zn} \times \mathrm{Ni}=$ prometryn $\times$ atrazine

prometryn $\times$ malathion $=\mathrm{Cd} \times \mathrm{Ni}$

prometryn $\times \mathrm{Cd}=$ malathion $\times \mathrm{Ni}$

It could be seen from the above alias structure of interactions that two-way interactions of fractional factorial design of resolution IV were fewer and more conducive to estimate than that of resolution III, which includes supplementary experiments (completely folded experiments and block experiments).

\section{The Prediction of Missing Data about Malathion Concentration}

Models of BP neural network have been used to approximate the missing value of marathon concentration in solution. The results of the experiment were divided into two groups: 55 samples $(80 \%)$ were used for neural network model training and the remaining 12 samples $(20 \%)$ were used as a verification sample to test the results of the model prediction. The number of hidden layer nodes was determined to be 50 by the dynamically constructed method. The minimum target error of 0.01 was selected through several preliminary experiments. The LM Bayesian regularization algorithm was adopted to train the model after normalizing data $[32,33]$. The model achieved target error after 16 steps of training.

The remaining 12 groups of data were chosen as the verification sample to test the model. The correlation coefficient $\mathrm{r}$ between the simulated value (from BP neural network) and measured values was $0.821(>0.80)$ and the bias was 0.37 , indicating that the result of neural network model simulations had high accuracy and the model simulation result was reliable. As is shown in Table 3, the predicted missing data font was bolded.

\section{Results and Analysis}

\section{Selection and Fit-Tested for Fixed Effect Model}

Because the levels of all experimental factors (fixed factors) were controllable, the fixed effects model of Minitab was adopted to do variance analysis on the noninteractive effects and two-way interactions of pollutant factors [34]. Firstly, the residual analysis module in Minitab software package was selected to fit the model. Then, variance analysis was used on the non-interactive effects and two-way interactions. Finally, the results of variance analysis would demonstrate whether they have a significant effect on the adsorption of malathion in sediment (significance level $\alpha=0.05$ ). Structure of the fixed effect model was chosen as follows:

$$
y_{i j k}=\mu+\tau_{i}+\beta_{j}+(\tau \beta)_{i j}+\delta_{k}+\varepsilon_{i j k}
$$

...where $\tau_{i}$ and $\beta_{j}$ denote main effects of two different pollutants, respectively; $(\tau \beta)_{i j}$ was the two-way interactions effect; $i$ and $j$ represented the levels of two different pollutants, respectively; $\delta_{k}$ denoted the effect of the $k$ block; $\varepsilon_{i j k}$ was the random error component of the model, which merged the other sources of variation in the experiment; $y_{i j k}$ was experimental testing value of the target pollutant.

Before using a fixed effects model, a fit test (i.e. normal assumption, independence assumption of residuals, and 
Table 3. The measured and predicted data for initial and equilibrium concentration of malathion in adsorption.

\begin{tabular}{|c|c|c|c|}
\hline $\begin{array}{l}\text { Class } \\
\text { number }\end{array}$ & $\begin{array}{c}\text { Equilibrium } \\
\text { concentration I }\end{array}$ & $\begin{array}{c}\text { Equilibrium } \\
\text { concentration II }\end{array}$ & $\begin{array}{c}\text { Initial } \\
\text { concentration }\end{array}$ \\
\hline 1 & 3.174 & 3.397 & 4.101 \\
\hline 2 & 1.535 & 1.445 & 1.536 \\
\hline 3 & 3.065 & 2.726 & 3.913 \\
\hline 4 & 2.653 & 3.197 & 4.422 \\
\hline 5 & 2.769 & 3.115 & 3.410 \\
\hline 6 & 3.382 & 3.793 & 4.109 \\
\hline 7 & 1.955 & 1.170 & 2.272 \\
\hline 8 & 3.797 & 3.864 & 3.962 \\
\hline 9 & 1.168 & 1.208 & 1.863 \\
\hline 10 & 1.708 & 1.484 & 2.681 \\
\hline 11 & 2.057 & 2.307 & 2.909 \\
\hline 12 & 2.378 & 2.415 & 2.515 \\
\hline 13 & 1.115 & 1.128 & 1.172 \\
\hline 14 & 1.802 & 1.863 & 2.915 \\
\hline 15 & 1.048 & 1.232 & 1.665 \\
\hline 16 & 2.730 & 3.473 & 4.134 \\
\hline 17 & 1.864 & 1.973 & 3.422 \\
\hline 18 & 2.139 & 2.370 & 2.684 \\
\hline 19 & 3.294 & 3.142 & 3.800 \\
\hline 20 & 2.436 & 3.063 & 3.643 \\
\hline 21 & 1.661 & 1.875 & 2.726 \\
\hline 22 & 2.602 & 2.519 & 2.884 \\
\hline 23 & 0.743 & 0.790 & 0.896 \\
\hline 24 & 0.497 & 0.502 & 1.220 \\
\hline 25 & 1.873 & 2.355 & 2.884 \\
\hline 26 & 2.509 & 3.011 & 3.522 \\
\hline 27 & 1.728 & 1.527 & 2.181 \\
\hline 28 & 0.401 & 0.591 & 1.168 \\
\hline 29 & 0.504 & 0.469 & 0.603 \\
\hline 30 & 2.140 & 2.102 & 2.665 \\
\hline 31 & 2.084 & 1.902 & 2.589 \\
\hline 32 & 0.824 & 0.810 & 0.878 \\
\hline
\end{tabular}

The bold text is the predicted data for initial and equilibrium concentration of malathion in adsorption.

homogeneity assumption of the variance) was carried out [35]. Only if the model meets the above conditions would it be suitable. The residual was the difference between the values from experiment and model estimation. The residual testing module in the Minitab software was used in inspection and the test results are shown in Fig. 1.
Table 4. Analysis of variance of non-interactive effects and two-way interactions of the pollutant facts concentrations affecting malathion in the sorption of heavy metals and pesticide system.

\begin{tabular}{|l|c|c|c|c|c|}
\hline \multicolumn{1}{|c|}{ Source } & DOF & Seq SS & Adj MS & F & P \\
\hline $\begin{array}{l}\text { Non-interactive } \\
\text { effects }\end{array}$ & 10 & 1.6346 & 0.1634 & 8.87 & 0.000 \\
\hline $\begin{array}{l}\text { Two-way } \\
\text { interactions }\end{array}$ & 21 & 1.8379 & 0.0875 & 4.75 & 0.000 \\
\hline Residual error & 32 & 0.5895 & 0.0184 & - & - \\
\hline Pure error & 32 & 0.5895 & 0.0184 & - & - \\
\hline Total & 63 & 4.0620 & - & - & - \\
\hline
\end{tabular}

In normal probability plot and histogram of residual, there is no abnormal point that deviated from the normal distribution, which satisfied the normality assumption of the model. Meanwhile, there was no positive or negative residual in the sequence of the residuals diagram, indicating that there was no violation in the assumption of independence in the model. It was also found that residuals and fitted values had no obvious pattern in fitted values of the residuals plot, which met homogeneity assumption of the variance. The residuals analysis showed that the fixed effects model could be used to make proper variance analysis for non-interactive effects and two-way interactions.

\section{Simulation Analysis and Conclusion \\ Screening and Analysis for Significant Impact Pollutants}

Effect estimation and variance analysis of the concentration level for each pollutant (heavy metals and pesticides in the system) on malathion adsorption onto the sediment was made. The factors that had significant influence were filtrated under significance level $\alpha=0.05$. Analyses of variances are shown in Table 4, and effect estimates are presented in Table 5.

The result of variance analysis in Table 4 showed that $P$ value of the non-interactive effects and two-way interactions was much lower than the significance level of 0.05 . Thus the non-interactive effects and two-way interactions of 10 pollutants had a significant influence on malathion adsorption onto the sediment as a whole. As can be seen in Table 5, non-interactive effects of the pollutants that had a significant influence were malathion $=0.2111, \mathrm{Zn}=0.1753$, atrazine $=0.1121$, and metalaxyl $=0.1767$. They all will promote malathion adsorption onto the sediment. Obviously, the most striking impact on malathion adsorption was $\mathrm{Zn}$. Gao's study about competitive adsorption of organic pesticides onto the sediment showed that the adsorption of nonpolar organic pesticides onto the sediment was inversely proportional to its solubility [36]. It is very likely that the presence of $\mathrm{Zn}$ could affect the solubility of malathion in water. 
It also can be seen from Table 5 that the two-way interactions had a significant impact on malathion adsorption onto the sediments. The related data are listed in detail below:

$\mathrm{Cu} \times \mathrm{Pb}=-0.2023$

$\mathrm{Zn} \times$ atrazine $=0.1656$

$\mathrm{Cu} \times$ atrazine $=-0.1001$

$\mathrm{Cu} \times$ prometryne $=0.0764$

$\mathrm{Cu} \times$ metalaxyl $=-0.0849$

$\mathrm{Cu} \times \mathrm{Ni}=-0.0759$

There are four two-way interactions $(\mathrm{Cu} \times \mathrm{Pb}$, $\mathrm{Cu} \times$ atrazine, $\mathrm{Cu} \times$ metalaxyl, and $\mathrm{Cu} \times \mathrm{Ni}$ ) which showed antagonistic effects on malathion adsorption onto the sediment. On the contrary, the others showed synergistic effects.

\section{The Contribution Rate of Non-Interactive Effects and Two-Way Interactions on Malathion Adsorption}

The pollutants that have significant non-interactive effects and two-way interaction effects were extracted. The degree of the effects and contribution rates for malathion adsorption are estimated and listed in Table 6. The formula used for calculating the contribution rate was as follows:

\section{Normal probability of residuals}

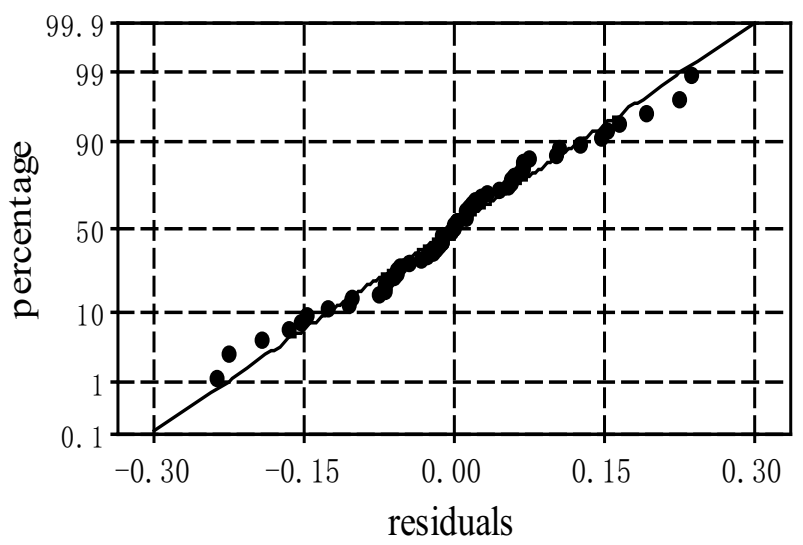

The histogram of residuals

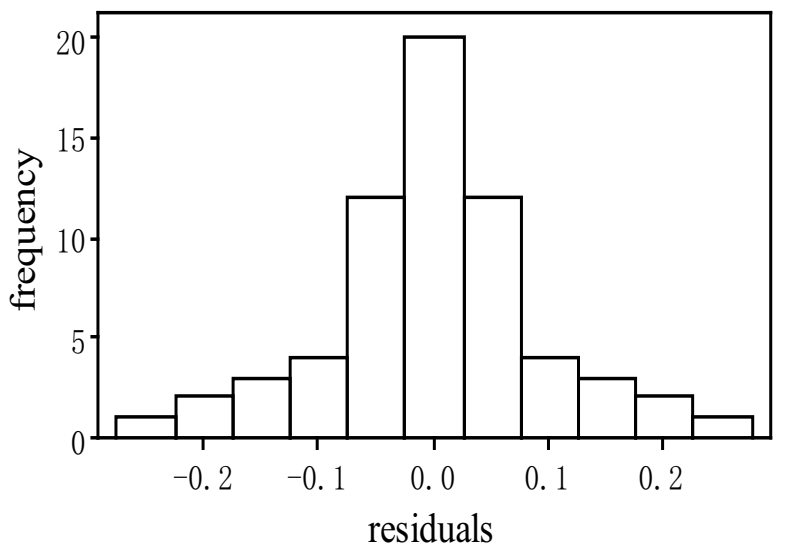

$$
\begin{gathered}
C(\text { contribution rate })= \\
{\left[E(\text { effect estimated }) \div\left(\sum E\right)\right] \times 100 \%}
\end{gathered}
$$

From Table 6, the total contribution rate of synergy effects from non-interactive effects and two-way interactions on malathion adsorption was $63.82 \%$; while the total antagonisms contribution rate was $36.18 \%$. The contribution rate of Zn's synergy was $13.69 \%$, which has the largest contribution rate except for malathion among all pollutants. In addition, the antagonism contribution rate of $\mathrm{Cu} \times \mathrm{Pb}$ for two-way interaction on malathion adsorption onto the sediment was $15.80 \%$, which could provide guidance in controlling malathion adsorption onto the sediments.

\section{Conclusions}

The fractional factorial design of resolution IV could effectively distinguish the mixed phenomenon of non-interactive effects and two-way interactions, and it largely reduced the complexity fractional factorial design of resolution III (completely folded), and eliminated the interference from block effects. The missing values of malathion adsorption in the experiment were solved through the

\section{Fitted values of residuals}
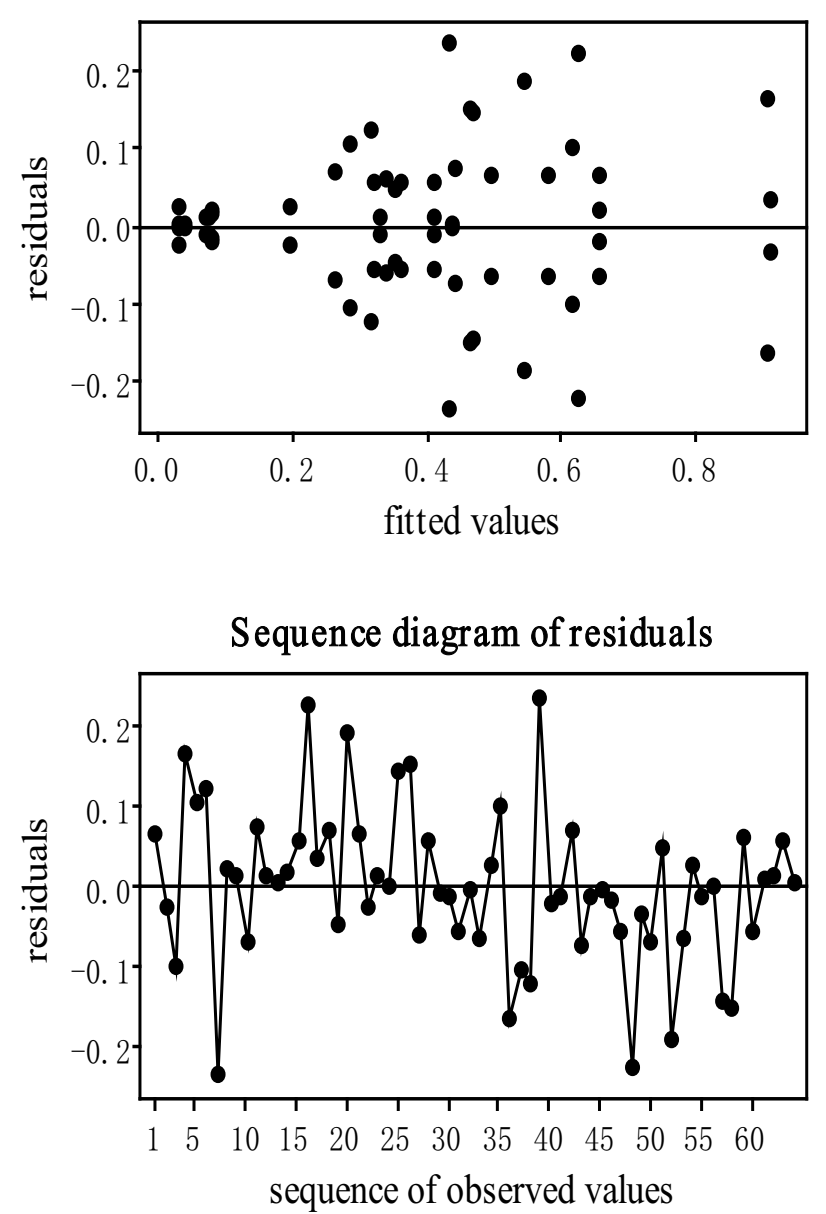

Fig. 1. The fit test of the model of ten pollutants adsorbed onto the sediments. 
Table 5. The estimates of non-interactive effects and two-way interactions of the pollutant facts concentrations affecting malathion in the sorption of heavy metals and pesticide system.

\begin{tabular}{|c|c|c|c|c|}
\hline Item & Effect estimates & Coefficient & Standard error of coefficient & $\mathrm{P}$ \\
\hline Constant & 0.3805 & 0.01697 & 22.43 & - \\
\hline $\mathrm{Cu}$ & 0.0174 & 0.0087 & 0.01697 & 0.611 \\
\hline $\mathrm{Zn}$ & 0.1753 & 0.0877 & 0.01697 & 0.000 \\
\hline $\mathrm{Pb}$ & -0.0049 & -0.0024 & 0.01697 & 0.887 \\
\hline $\mathrm{Cd}$ & 0.0386 & 0.0193 & 0.01697 & 0.263 \\
\hline $\mathrm{Ni}$ & -0.0437 & -0.0219 & 0.01697 & 0.207 \\
\hline Atrazine & 0.1121 & 0.0560 & 0.01697 & 0.002 \\
\hline Malathion & 0.2111 & 0.1056 & 0.01697 & 0.000 \\
\hline Prometryn & -0.0106 & -0.0053 & 0.01697 & 0.756 \\
\hline Dimethoate & -0.0674 & -0.0337 & 0.01697 & 0.056 \\
\hline Metalaxyl & 0.0767 & 0.0384 & 0.01697 & 0.031 \\
\hline $\mathrm{Cu} \times \mathrm{Zn}$ & -0.0469 & -0.0235 & 0.01697 & 0.176 \\
\hline $\mathrm{Cu} \times \mathrm{Pb}$ & -0.2023 & -0.1012 & 0.01697 & 0.000 \\
\hline $\mathrm{Cu} \times \mathrm{Cd}$ & 0.0032 & 0.0016 & 0.01697 & 0.925 \\
\hline $\mathrm{Cu} \times \mathrm{Ni}$ & -0.0759 & -0.0379 & 0.01697 & 0.032 \\
\hline $\mathrm{Cu} \times$ Atrazine & -0.1001 & -0.0500 & 0.01697 & 0.006 \\
\hline $\mathrm{Cu} \times$ Malathion & 0.0397 & 0.0198 & 0.01697 & 0.251 \\
\hline $\mathrm{Cu} \times$ Prometryn & 0.0764 & 0.0382 & 0.01697 & 0.031 \\
\hline $\mathrm{Cu} \times$ Dimethoate & -0.0175 & -0.0087 & 0.01697 & 0.610 \\
\hline $\mathrm{Cu} \times$ Metalaxyl & -0.0849 & -0.0424 & 0.01697 & 0.018 \\
\hline $\mathrm{Zn} \times \mathrm{Pb}$ & -0.0621 & -0.0310 & 0.01697 & 0.077 \\
\hline $\mathrm{Zn} \times \mathrm{Cd}$ & -0.0206 & -0.0103 & 0.01697 & 0.547 \\
\hline $\mathrm{Zn} \times \mathrm{Ni}$ & 0.0093 & 0.0047 & 0.01697 & 0.785 \\
\hline $\mathrm{Zn} \times$ Atrazine & 0.1656 & 0.0828 & 0.01697 & 0.000 \\
\hline $\mathrm{Zn} \times$ Malathion & -0.0299 & -0.0150 & 0.01697 & 0.384 \\
\hline $\mathrm{Zn} \times$ Prometryn & 0.0273 & 0.0136 & 0.01697 & 0.427 \\
\hline $\mathrm{Pb} \times \mathrm{Cd}$ & 0.0001 & 0.0001 & 0.01697 & 0.997 \\
\hline $\mathrm{Pb} \times \mathrm{Ni}$ & 0.0479 & 0.0239 & 0.01697 & 0.168 \\
\hline $\mathrm{Pb} \times$ Atrazine & 0.0057 & 0.0028 & 0.01697 & 0.869 \\
\hline $\mathrm{Pb} \times$ Malathion & 0.0524 & 0.0262 & 0.01697 & 0.132 \\
\hline $\mathrm{Cd} \times \mathrm{Ni}$ & -0.0462 & -0.0231 & 0.01697 & 0.183 \\
\hline $\mathrm{Cd} \times$ Atrazine & -0.0197 & -0.0098 & 0.01697 & 0.566 \\
\hline
\end{tabular}

The bold text is the pollution factor which has a significant impact on malathion adsorption onto the sediments.

method of the BP neural network. Based on this experimental design and combined with the fixed effects model, we screened the pollutants with significant non-interaction effects and two-way interactions on the target contaminants (malathion). According to the result, the total synergy contribution rate of non-interactive effects and two-way inter- actions on malathion adsorption onto the sediment was $63.82 \%$. The contribution rate of Zn's synergy was $14.7 \%$, which was the highest contribution rate except malathion among all pollutant factors. The total negative contribution rate was $36.18 \%$, and the highest antagonism contribution rate among all two-way interactions was $\mathrm{Cu} \times \mathrm{Pb} 16.9 \%$. 
Table 6. The contribution rates of the facts with a significant impact to malathion adsorption onto the sediments.

\begin{tabular}{|l|c|c|c|}
\hline \multirow{2}{*}{ Factor } & \multirow{2}{*}{$\begin{array}{c}\text { Effect } \\
\text { estimates }\end{array}$} & \multicolumn{2}{c|}{ Rate of contribution } \\
\cline { 3 - 4 } Malathion & 0.2111 & $16.49 \%$ & - \\
\hline $\mathrm{Zn}$ & 0.1753 & $13.69 \%$ & - \\
\hline Atrazine & 0.1121 & $8.76 \%$ & - \\
\hline Metalaxyl & 0.0767 & $5.99 \%$ & - \\
\hline $\mathrm{Cu} \times \mathrm{Pb}$ & -0.2023 & - & $15.80 \%$ \\
\hline $\mathrm{Cu} \times \mathrm{Metalaxyl}$ & -0.0849 & - & $6.63 \%$ \\
\hline $\mathrm{Zn} \times \mathrm{Atrazine}$ & 0.1656 & $12.93 \%$ & - \\
\hline $\mathrm{Cu} \times \mathrm{Atrazine}$ & -0.1001 & - & $7.82 \%$ \\
\hline $\mathrm{Cu} \times \mathrm{Prometryn}$ & 0.0764 & $5.97 \%$ & - \\
\hline $\mathrm{Cu} \times \mathrm{Ni}$ & -0.0759 & - & $5.93 \%$ \\
\hline $\mathrm{Total}$ & - & $63.82 \%$ & $36.18 \%$ \\
\hline
\end{tabular}

\section{Acknowledgements}

This work was supported by the National Natural Science Foundation of China (No. 50879025).

\section{References}

1. KUMARASAMY M.V. Deoxygenation and reaeration coupled hybrid mixing cells based pollutant transport model to assess water quality status of a river. Int. J. Environ. Res., 9, (1), 341, 2015.

2. SULTANA M.S., JOLLY Y.N., YEASMIN S., ISLAM A., SATTER S., TAREQ S.M. Chapter 12 - Transfer of heavy metals and radionuclides from soil to vegetables and plants in Bangladesh. Soil Remediation and Plants, Available online 6 September, 331-366, 2015.

3. UDEIGWE T.K., TEBOH J.M., EZE P.N. Implications of $\mathrm{Pb}$ crop production practices on environmental quality and human health. J. Environ. Manage., 151, 267, 2015.

4. D'AMATO G., CECCHI L., D'AMATO M. Urban air pollution and climate change as environmental risk factors of respiratory allergy: an update. J. Invest. Allerg. Clin., 20, (2), 95, 2010.

5. CONCAS A., ARDAU C., CRISTINI A. Mobility of heavy metals from tailings to stream waters in a mining activity contaminated site. Chemosphere, 63, (2), 244, 2006.

6. GOVIL P.K., SORLIE J.E., MURTHY N.N. Soil contamination of heavy metals in the Katedan industrial development area, Hyderabad, India. Environ. Monit. Assess., 140, (1-3), 313, 2008.

7. CLEMENS S. Toxic metal accumulation, responses to exposure and mechanisms of tolerance in plants. Biochimie, 88, (11), 1707, 2006.

8. SINGER R.S., COX L.A., DICKSON J.S. Modeling the relationship between food animal health and human foodborne illness. Prev. Vet. Med., 79, (2-4), 186, 2007.
9. SUN Z.G., WANG L.H., ZHOU Q. Effects and mechanisms of the combined pollution of lanthanum and acid rain on the root phenotype of soybean seedlings. Chemosphere, 93, (2), 344, 2013.

10. BILLIONNET C., SHERRILL D., ANNESI-MAESANO I. Estimating the health effects of exposure to multi-pollutant mixture. Ann. Epidemiol., 22, (2), 126, 2012.

11. WANIA F., MACKAY D. The evolution of mass balance models of persistent organic pollutant fate in the environment. Environ. Pollut., 100, (1-3), 223, 1999.

12. WALNA B. Interdisciplinary study of post-agricultural pollution in the Wielkopolski National Park (Poland). Journal of Integrative Environmental Sciences, 10, (1), 17, 2013.

13. MOREIRA J.C., PERES F., SIMOES A.C. Groundwater and rainwater contamination by pesticides in an agricultural Region of Mato Grosso State in Central Brazil. Ciencia and Saude Coletiva, 17, (6), 1557, 2012.

14. VIJVER M.G., SPIJKER J., VINK J.P.M. Determining metal origins and availability in fluvial deposits by analysis of geochemical baselines and solid-solution partitioning measurements and modelling. Environ. Pollut., 156, (3), 832, 2008.

15. LI Y., WANG X.L., WANG Y. Comparison of $\mathrm{Pb}$ and $\mathrm{Cd}$ adsorption to the surface coatings and surficial sediments collected in Xianghai Wetland. J. Environ. Sci., 17, (1), 126, 2005.

16. VELAZQUEZ M.A., LUIS P.J., ORTEGA M. Study of the distribution of boron in water sources of the Duero river basin, Mexico, using multivariate statistical analysis. Revista Internacional De Contaminacion Ambiental, 27, (2), 19, 2011

17. FOSSO-KANKEU E., MULABA-BAFUBIANDI A.F., MAMBA B.B. Prediction of metal-adsorption behaviour in the remediation of water contamination using indigenous microorganisms. J. Environ. Manage., 92, (10), 2786, 2011.

18. NOVAKOVA T., MATYS G.T., BABEK O. Distinguishing regional and local sources of pollution by trace metals and magnetic particles in fluvial sediments of the Morava River, Czech Republic. Journal of Soils and Sediments, 13, (2), 460, 2013.

19. RUIZ F., GONZALEZ-REGALADO M.L., MUNOZ J.M. Distribution of heavy metals and pollution pathways in a shallow marine shelf: assessment for a future management. International Journal of Environmental Science and Technology, 11, (5), 1249, 2014.

20. RUBINOS D. A., IGLESIAS L., DÍAZ-FIERROS F., BARRAL M. T. Interacting effect of $\mathrm{pH}$, phosphate and time on the release of arsenic from polluted river sediments (Anllo 'ns River, Spain). Aquat. Geochem., 17, 281, 2011

21. GUO Z.Y., DONG D.M., HUA X.Y., ZHANG L.W., ZHU S.J., LAN X.H., LIANG D.P. Cr and As decrease lindane sorption on river solids. Environmental Chemistry Letters, 13, (1), 111, 2015.

22. YOSHII K., TONOGAI Y., UENO H. Malathion residue in wheat kernels is degraded by thion organophosphorus pesticide-specific carboxylesterase. J. Health Sci., 52, (3), 221, 2006.

23. MA J., PAN G.X., WAN H.F. The toxicity, residues and the prospect of organic phosphorus pesiticide. Ecology and Environment, 12, (2), 213, 2003.

24. DYMKOWSKA-MALESA M., SZPARAGA A., CZERWINSKA E. Evaluation of polychlorinated biphenyls content in chosen vegetables from warmia and mazury region. Rocznik Ochrona Srodowiska, 16, (1), 290, 2014. 
25. DURAK D., UZUN, F.G., KALENDER S. Malathioninduced oxidative stress in human erythrocytes and the protective effect of vitamins $\mathrm{C}$ and $\mathrm{E}$ in vitro. Environ. Toxicol., 24, (3), 235, 2009.

26. KHARE A., SINGH S., SHRIVASTAVA K. Malathion induced biochemical changes in the kidney of fresh water fish clarias batrachus. Journal of Ecotoxicology and Environmental Monitoring, 10, (1), 11, 2000.

27. SCHWARZBAUER J., SINDERN S., DSIKOWITZKY L. Geochemical analysis of Lake Bant sediments to ascertain inorganic and organic indicators for warfare residues. Journal of Soils and Sediments, 10, (1), 104, 2010.

28. LI Y., WANG M., ZHANG C., GAO Q. Law of competitive adsorption of $\mathrm{Zn}$ and variety of pollutants based on fractional factorial design. Journal of Central South University (Science and Technology), 44, (5), 2150, 2013.

29. ZHANG Y., GUO D.S., LI Z. Common nature of learning between back-propagation and Hopfield-type neural networks for generalized matrix inversion with simplified models. IEEE Transactions on Neural Networks and Learning Systems, 24, (4), 579, 2013.

30. LI Y., WANG M., ZHANG C., GAO Q. Law of competitive adsorption of zinc and variety of pollutants based on fractional factorial design. Journal of Central South University, 44, (5), 2150, 2013.

31. DOUGLAS C. Montgomery. Design and Analysis of experiments [M]. Posts \& telecom press, 2009.

32. BAGHERI G., VASHEGHANI-FARAHANI E., ARDJMAND M. Artificial neural networks modeling of release of olanzapine from glycerol monooleate matrices. Letters in Drug Design and Discovery, 11, (5), 636, 2014.

33. AL-BATAH M.S., ISA N.A.M., ZAMLI K.Z. A novel aggregate classification technique using moment invariants and cascaded multilayered perceptron network. Int. J. Miner. Process., 92, (1-2), 92, 2009

34. BROOMS A.C. Experimental statistics using Minitab. J. Roy. Stat. Soc. A Sta., 172, (2), 533, 2009.

35. WANG D.X., CONERLY M.D. Evaluating the power of Minitab's data subsetting lack of fit test in multiple linear regressions. J. Appl. Stat., 35, (1), 115, 2008.

36. GAO Q., WANG A., LI Y. Combined effect of co-existing heavy metals and organophosphate pesticide on absorption of atrazine to river sediments. Korean J. Chem. Eng., 28, (5), 1200, 2011. 
